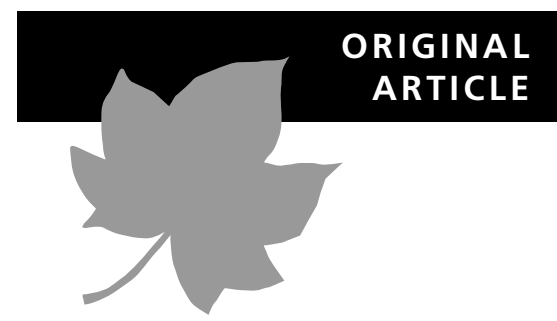

\title{
Macro-scale bird species richness patterns of the East Asian mainland and islands: energy, area and isolation
}

\author{
Tzung-Su Ding ${ }^{1}$, Hsiao-Wei Yuan ${ }^{1}$, Shu Geng ${ }^{2}$, Chao-Nien $\mathrm{Koh}^{3,4}$ and \\ Pei-Fen Lee ${ }^{3 *}$
}

${ }^{1}$ School of Forestry and Resource Conservation, National Taiwan University, No. 1, Sec. 4, Roosevelt Road, Taipei 106, Taiwan, ${ }^{2}$ Department of Agronomy and Range Science, University of California, One Shield Avenue, Davis, CA 95616, USA, ${ }^{3}$ Institute of Ecology and Evolutionary Biology, and Department of Life Science, National Taiwan University, Taipei and ${ }^{4}$ Division of Forest Protection, Taiwan Forestry Research Institute, No. 53, Nan-Hai Road, Taipei 100, Taiwan
${ }^{*}$ Correspondence: Pei-Fen Lee, Institute of Ecology and Evolutionary Biology, National Taiwan University, Taipei 106, Taiwan. E-mail: leepf@ntu.edu.tw

\section{ABSTRACT}

Aim To create a map of bird species richness (BSR) in East Asia and to examine the effect of area, isolation, primary productivity, topographic heterogeneity, and human population density on BSR.

Location East Asia (from $70^{\circ} \mathrm{E}$ to $180^{\circ} \mathrm{E}$ longitude), including the eastern half of the Palaearctic Region, the entire Oriental Region, and the entire Wallacea Subregion.

Methods The breeding ranges of 2406 terrestrial bird species were mapped and overlaid to create a species richness map. The BSR map was transformed into a $100 \times 100 \mathrm{~km}$ quadrat system, and BSR was analysed in relation to land area, average normalized difference vegetation index (NDVI), elevation range, and average population density.

Results In general, BSR declined from the Tropics to the Arctic. In mainland East Asia, however, BSR was highest around the Tropic of Cancer, and fluctuated between $30^{\circ}$ and $50^{\circ} \mathrm{N}$. Islands had lower BSR than adjacent mainland areas. The NDVI was strongly positively correlated with BSR in mainland areas and on islands. For mainland areas, NDVI explained $65 \%$ of the BSR variation, and topographic heterogeneity explained an additional $6 \%$ in ordinary least-squares regression. On islands, NDVI explained $66 \%$ of BSR variation, island area explained $13 \%$, and distance to mainland accounted for $1 \%$.

Main conclusions In East Asia, we suggest that primary productivity is the key factor underpinning patterns of BSR. Primary productivity sets the upper limits of the capacity of habitats to support bird species. In isolated areas such as islands and peninsulas, however, BSR might not reach the richness limits set by primary productivity because the degree of isolation and area size also can affect species richness. Other factors, such as spatial heterogeneity, biotic interactions, and perturbations, may also affect species richness. However, their effects are secondary and are not as strong as primary productivity, isolation, and area size.

\section{Keywords}

East Asia, energy availability, energy limitation theory, island biogeography, latitudinal gradient, primary productivity, spatial heterogeneity, species diversity.

\section{INTRODUCTION}

One of the most consistent patterns in biogeography is the latitudinal diversity gradient in which species richness peaks in the Tropics and declines towards the poles (Hillebrand, 2004). The processes creating this pattern have, however, remained controversial (Willig et al., 2003). Because the latitudinal diversity gradient is so widespread and consistent, earlier ecologists (e.g. MacArthur \& Connell, 1966) believed there should be a general explanation for this pattern. Over the years, more than 30 hypotheses have been proposed to explain the latitudinal diversity gradient (examples in Rosenzweig, 1995; Brown \& Lomolino, 1998; Willig et al., 2003). There are at least three reasons for this great diversity of competing 
hypotheses. First, the hypotheses are not mutually exclusive. Many of the proposed factors could have operated together, either sequentially or concurrently, to affect current latitudinal patterns of species richness (Brown \& Lomolino, 1998; Whittaker et al., 2001). Second, ecologists have to rely on comparative studies that do not provide clear cause-effect relationships. Third, most investigators have tested only one hypothesis, instead of testing multiple hypotheses simultaneously.

Some hypotheses that are based on biotic interactions, including the competition hypothesis (Dobzhansky, 1950) and predation hypothesis (Paine, 1966), are tautological because they generally assume higher species richness in the Tropics (Rohde, 1992). Although biotic interactions surely play significant roles in determining species richness, hypotheses based on biotic interactions were often treated as secondary factors in broad-scale studies (Rohde, 1992; Brown \& Lomolino, 1998). Others, such as the environmental stability hypothesis (Klopfer, 1959), lack sufficient supporting evidence (Rohde, 1992). Some authors (Rohde, 1992; Rosenzweig, 1995; Gaston \& Blackburn, 2000; Rahbek \& Graves, 2001) think that the most promising hypotheses are the time hypothesis (Fischer, 1960), the area hypothesis (Terborgh, 1973; Rosenzweig, 1995), and the energy limitation hypothesis (Connell \& Orias, 1964; Wright, 1983). The time hypothesis holds that lower latitudes have remained relatively free of Pleistocene glaciations and severe climatic disruptions, enabling more species to persist and evolve than at higher latitudes (Fischer, 1960). The area hypothesis argues that, because the Earth is a sphere, there is more land area at lower latitudes, which leads to greater species richness through the reduction of extinction rates (Rosenzweig, 1995) and an increase in the rate of allopatric speciation (Terborgh, 1973). The energy limitation hypothesis maintains that, because the Tropics usually receive higher solar radiation and precipitation, primary productivity is higher. This provides a wider resource base and enables more species to co-occur by increasing population sizes (Connell \& Orias, 1964; Wright, 1983).

Ideally, studies on the latitudinal gradient should encompass an area that extends from the Tropics to the Arctic. Partial coverage may result in misleading patterns. North America, South America, and East Asia are the only continents that extend from the Tropics to the polar regions. However, few, if any, distributional patterns of species richness of major taxa in East Asia (Asia east of $70^{\circ} \mathrm{E}$ longitude) have been mapped, despite the large share of global biodiversity in this area.

East Asia has at least four distinct geographical characteristics. First, there is a chain of islands that extends from the Tropics to the Arctic and displays great variation in size and distance from the mainland. Second, tropical East Asia is mostly composed of islands. Eurasian extensions into the Tropics are all peninsulas, such as the Malay Peninsula and India, and are isolated to some degree from the bulk of Eurasia. Third, East Asia has a distinct latitudinal gradient in primary productivity. In western Asia, Africa, Australia, North America, and South American, deserts are located mainly between $20^{\circ}$ and $30^{\circ}$ latitude. In East Asia, as a result of the blocking effect of the Tibetan Plateau (An et al., 2001), the deserts occur mainly from $35^{\circ}$ to $45^{\circ} \mathrm{N}$ latitude, and precipitation and primary productivity are high from $20^{\circ}$ and $30^{\circ} \mathrm{N}$ (Matsushita \& Tamura, 2002). Fourth, East Asia contains half of the world's population. There has been extensive cultivation and modification of the natural vegetation over thousands of years. All these characteristics make East Asia a unique site for studying spatial patterns of species richness at the continental scale.

Because of their well-studied taxonomy and distribution, birds have been frequently used in studies of species diversity at broad spatial scales. Of the total of 9702 bird species on the Earth, more than 2466 species breed in East Asia, and 1906 species are found only in East Asia (summarized from Monroe \& Sibley, 1993). The main objectives of this study were: (1) to create a map of bird species richness (BSR) in East Asia; and (2) to examine the relationship between BSR and area, isolation, primary productivity, topographic heterogeneity, and human population density.

\section{METHODS}

The study area was defined as Asia between $70^{\circ} \mathrm{E}$ and $180^{\circ} \mathrm{E}$ longitude (Fig. 1). Zoogeographically, this area includes the eastern half of the Palaearctic Region, the entire Oriental Region, and the entire Wallacea Subregion (a part of the Australian Region), and extends from the Lesser Sunda Islands $\left(10^{\circ} \mathrm{S}\right)$ to Severnaya Zemlya $\left(80^{\circ} \mathrm{N}\right)$. Pelagic birds, which feed primarily on marine food sources and usually have nomadic distribution on land, were excluded in this study. These pelagic species included Laridae (gulls, terns, auks), Phaethontidae (tropic birds), and Sulidae (boobies). A total of 2406 terrestrial bird species were included. The breeding ranges of these 2406 terrestrial bird species were obtained from sources published between 1975 and 2000 (see Appendix S1 in Supplementary Material). The breeding range of each species was transcribed onto a Mercator projection map of the study area and digitized into GIS polygon coverage in ARC/INFO (ESRI, Redlands, USA). The error of the transcription process was less than $100 \mathrm{~km}$. The breeding ranges of the 2406 species were overlaid to create the BSR layer. A species checklist and an atlas of their distributions in the study area are provided on the website http://asianbird.zo.ntu.edu.tw/.

\section{Quadrat system}

Many studies of species richness on a continental scale have used latitude-longitude quadrats ( such as $1^{\circ} \times 1^{\circ}, 5^{\circ} \times 5^{\circ}$ ) as units of analysis. The land area of quadrats was either unjustified (e.g. Currie \& Paquin, 1987) or included as one possible factor for the observed spatial patterns of species richness (e.g. Kerr \& Packer, 1997; Rahbek \& Graves, 2001; Henningsson \& Alerstam, 2005). The pitfall with this method is that quadrat area systematically correlates with latitude: the area of latitude-longitude quadrats decreases with increasing latitude. Justifying the land area of latitude-longitude quadrats 
Figure 1 Species richness map overlaid by the breeding ranges of 2406 bird species in East Asia. Bird species richness was highest at the base of the Indochina Peninsula and lowest in northern Siberia, the Gobi and Taklimakan deserts and the Tibetan Plateau. Islands had lower bird species richness than adjacent areas in mainland Asia.



before regression analyses could statistically obscure the correlation between species richness and other factors that are dependent on latitude (e.g. primary productivity, temperature). We bypassed this problem by using a $100 \times 100 \mathrm{~km}$ quadrat as the analysis unit (grain) for regression analyses. We established a system of equal-area quadrats using the LambertAzimuth equal-area projection. Those quadrats with land area less than $3000 \mathrm{~km}^{2}$ (30\% of the quadrat size) were excluded. In total, 3433 quadrats met the criterion, of which 345 were on islands.

Setting the threshold as $30 \%$ means that many small islands are included. Those small islands contain many endemic species and are critical for this study. Raising the threshold to $60 \%$ or $80 \%$ would unfortunately exclude many islands (e.g. Lesser Sunda islands, Molucca, Palawan, etc.) that have detailed and reliable lists of breeding species and special meanings in biogeography. We selected those quadrats with land area between 3000 and $9000 \mathrm{~km}^{2}$, and found that BSR did not significantly correlate with land area of grid (slope $=-0.001, F=0.041, P=0.84$ ). We also divided all quadrats into four levels of land area (3000-5999, 6000-7999,
8000-8999, 9000-10000 $\mathrm{km}^{2}$ ), and found no significant difference in species richness $(F=1.93, P=0.123)$.

\section{Environmental factors}

Terrestrial ecosystem productivity was estimated by the advanced very high resolution radiometer-normalized difference vegetation index (AVHRR-NDVI). NDVI is a measure derived by dividing the difference between near-infrared and red reflectance measurements by their sum (Tucker, 1979). It is highly correlated with green-leaf biomass, green-leaf area, and absorbed photosynthetically active radiation (APAR), and has been viewed as providing reasonable representations of net primary productivity and vegetative growth of terrestrial ecosystems at continental and global scales (Ustin et al., 1991). The daily NDVI composites tend to be skewed by cloud contamination. To minimize this problem, researchers create monthly NDVI composites using the maximum value composite method: the maximum daily NDVI value is assigned to each individual pixel location (Holben, 1986). During the monsoons, however, the monthly composites for East Asia 


\section{T.-S. Ding et al.}

were still skewed by cloud contamination. Therefore, the 144 monthly NDVI composites for 12 years (1987-2000) (Loveland et al., 2000) were combined by the maximum value composite method to create historic, monthly NDVI composites. We employed average annual NDVI in our analyses, instead of average NDVI of certain seasons (e.g. Hawkins, 2004), based on the following three reasons. First, there is often a time lag between the energy conversion of plants and the energy consumption of animals. Birds in breeding seasons might directly or indirectly utilize net primary productivity produced in non-breeding seasons. Second, birds in tropical regions are usually not consistent in their breeding season, and consequently it is difficult to define a consistent 'breeding season' for both temperate and tropical species. Third, the mean NDVI from March to August was highly correlated with the mean annual NDVI in our study $\left(R^{2}=0.88\right)$. Using either annual or summer NDVI would not change the trend of the relationships.

Variations in topography and land cover both contribute to landscape heterogeneity. Because there is not an accurate, detailed map of land cover in East Asia, and elevation profoundly influences the abiotic environment and biotic communities, we used the elevation range of each quadrat (maximum minus minimum elevation recorded in each quadrat) as an estimate of topography heterogeneity and landscape heterogeneity. The elevation range was calculated from the Global 30 Arc Second Elevation Data Set (GTOPO30).

Human population density data were obtained from the ESRI ArcAtlas data set (ESRI (Environmental System Research Institute), 1996). The data were compiled from various sources, including national population censuses and United Nation demographic yearbooks. Most data bases were established between 1981 and 1994. The population density coverage was overlaid on the quadrat system to calculate the average population density of each quadrat.

Island area and distance to the mainland were calculated for the 345 quadrats located on islands. Island area was directly calculated from the country coverage in the ESRI ArcAtlas data set (ESRI (Environmental System Research Institute), 1996) that had been converted to the Lambert-Azimuth equal-area projection. Distance to mainland was calculated as the minimum distance from an island to the mainland at the two-point equidistant projections that do not distort geographical distances.

\section{Analyses}

The ranges of the 2406 bird species were overlaid on the quadrat system, and the area of each species distribution in each quadrat was calculated. If the distribution of a species covered more than $25 \%$ of the land area of the quadrat, it was 'present' in that quadrat; otherwise, 'absent' was recorded. To test whether the $25 \%$ cut-off point significantly affected the results, we calculated the species richness of the Anseriformes and Sylviidae at cut-off points of $0 \%, 25 \%, 50 \%$, and $100 \%$.
The species richness values associated with each cut-off point were highly correlated with each other $(R>0.98$ for all pairwise comparisons). Binary distribution matrices for all 2406 species were added to create a layer of BSR in raster format.

All environmental factor data layers were transformed to the Lambert-Azimuth equal-area projection and overlaid on the $100 \times 100 \mathrm{~km}$ quadrat system. The average NDVI (mean of the 1987-2000 historic monthly NDVI), elevation range, and average population density of each quadrat were calculated. In this study, BSR was spatially autocorrelated among the quadrats in mainland Asia. Spatial autocorrelation may inflate Type I error (Diniz-Filho et al., 2003). Therefore, we used both ordinary least-squares regression (OLS) and conditional autoregressive (CAR) models to determine the variation in BSR explained by average NDVI, elevation range, average population density, and land area of quadrat. The CAR models assume that the response at each quadrat is a function not only of the explanatory variables but also of the values of the response variable in neighbouring quadrats (Lichstein et al., 2002; Tognelli \& Kelt, 2004). The analyses of CAR models were performed with S-Plus software (Kaluzny et al., 1998). For quadrats located on islands, the spatial autocorrelation in BSR was not significant. Therefore we used OLS models to account for the variation in BSR, and explanatory variables included average NDVI, elevation range, average population density, island area, distance to mainland, and land area of quadrat.

\section{RESULTS}

\section{Bird species richness}

The species richness map overlain by the breeding ranges of 2406 species showed that BSR was highest at the base of the Indochina peninsula, especially where Burma borders India and China (Fig. 1). In this region, the Himalayas descend into tropical lowlands, topographic variation is high, and human population is low. These species richness hotspots extended from $20^{\circ}$ to $30^{\circ} \mathrm{N}$ latitude, with maximum BSR near the Tropic of Cancer. In contrast, northern Siberia, the Gobi and Taklimakan deserts, and the Tibetan Plateau had lower BSR. All islands had lower BSR than adjacent mainland areas (Fig. 1).

BSR in the $100 \times 100 \mathrm{~km}$ quadrats ranged from 5 to 510 species. In general, BSR declined from the Tropics to the Arctic (Fig. 2a). However, there were two notable exceptions on the mainland. First, although the fitted DWLS (distance-weighted least-squares) curve for mainland BSR peaked around the equator, quadrats with maximum BSR were located near $25^{\circ} \mathrm{N}$, not at the equator. Second, in mainland East Asia, BSR rapidly decreased from $25^{\circ}$ to $40^{\circ} \mathrm{N}$ and increased again from $40^{\circ}$ to $50^{\circ} \mathrm{N}$.

\section{Area}

The study area comprised 93\% mainland and 7\% islands (Fig. 2b). The southernmost mainland point was $2^{\circ} \mathrm{N}$. Within 

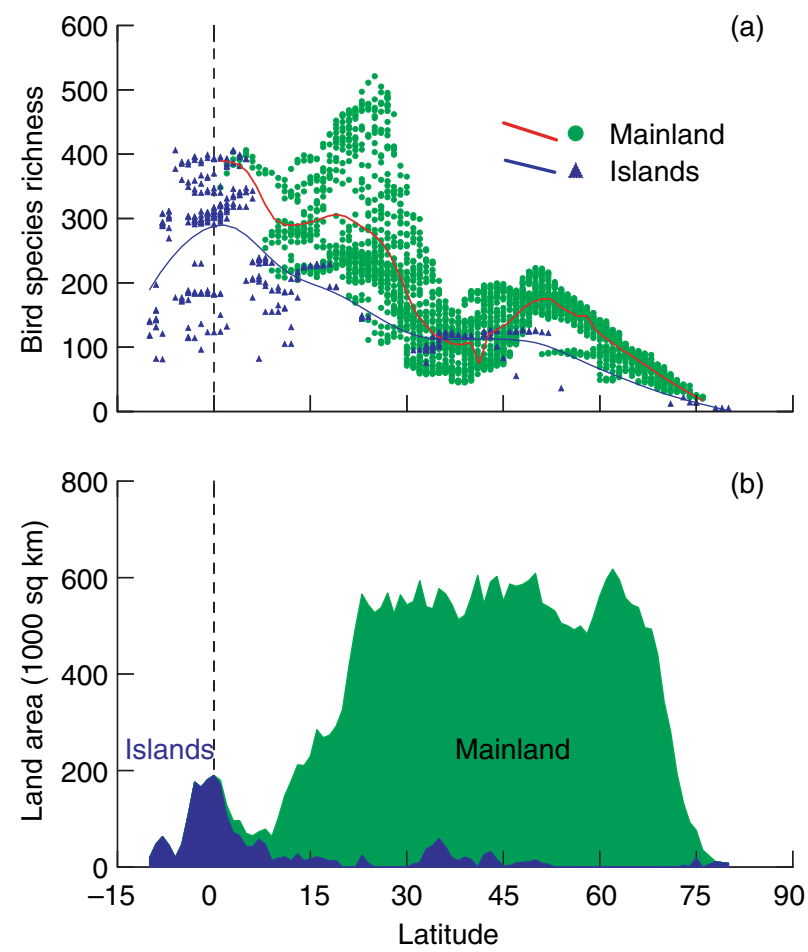

Figure 2 The distribution of (a) bird species richness and (b) land area along the latitudinal gradient in East Asia. Green circles denote mainland quadrats, and blue triangles denote island quadrats. The lines represent the trends found by distanceweighted least-squares fits to the data.

the study area, only $1 \%$ of the mainland was south of $10^{\circ} \mathrm{N}$, $14 \%$ lay within the Tropics $\left(23.5^{\circ} \mathrm{S}-23.5^{\circ} \mathrm{N}\right)$, and $78 \%$ lay within the temperate zone $\left(23.5^{\circ} \mathrm{N}-66.5^{\circ} \mathrm{N}\right)$. Islands extended from $10^{\circ} \mathrm{S}$ to $80^{\circ} \mathrm{N}$, but $80 \%$ of the island area was in the Tropics and $73 \%$ was between $10^{\circ} \mathrm{S}$ and $10^{\circ} \mathrm{N}$. Land area of island quadrats was, on average, $80 \%$ of the land area of mainland quadrats. Land area of quadrats showed no significant relationship with BSR of quadrats (simple linear regression, both variables log-transformed, slope $=-0.004$, $\left.R^{2}<0.001, P=0.929\right)$.

On mainland East Asia, BSR did not correlate closely with land area along the latitudinal gradient (Fig. 2). To determine the correlation between land area and BSR along the latitudinal gradient, the mainland was divided into latitudinal bands of $1^{\circ}, 5^{\circ}, 10^{\circ}$, or $20^{\circ}$, and the land area and BSR of each band were calculated (Table 1 ). For the $5^{\circ}$ and $20^{\circ}$ bands, BSR was not correlated with land area. For the $10^{\circ}$ bands, land area negatively correlated with BSR and explained only $4 \%$ of the variation in BSR.

On island quadrats, however, land area correlated strongly with BSR. After both were log-transformed, BSR of island quadrats correlated significantly with island area in a simple linear regression analysis (intercept $=2.19$, slope $=0.26$, $R^{2}=0.39, P<0.001$ for both coefficients). This species-area relationship is expressed by the power model:

$\mathrm{BSR}=2.19$ Area $^{0.26}$.
Table 1 Relationships of land area and species richness in various widths of latitudinal band in mainland East Asia. Land area did not correlate significantly with bird species richness along the latitudinal gradient. The land area and the number of bird species within $5^{\circ}, 10^{\circ}$ and $20^{\circ}$ latitudinal bands in mainland East Asia were calculated and log-transformed to fit the power model, $\log (\mathrm{BSR})=c+z \log ($ Area $)$

\begin{tabular}{|c|c|c|c|c|c|}
\hline $\begin{array}{l}\text { Band } \\
\text { width }\end{array}$ & $n$ & $z$ & $R^{2}$ & $t$ & $\begin{array}{l}\text { Prob. } \\
\text { for } z>0\end{array}$ \\
\hline $5^{\circ}$ & 15 & 0.005 & 0.00 & 0.028 & 0.98 \\
\hline $10^{\circ}$ & 7 & -0.108 & 0.04 & -0.506 & 0.64 \\
\hline $20^{\circ}$ & 4 & -0.052 & 0.00 & 0.067 & 0.95 \\
\hline
\end{tabular}

\section{Primary productivity}

Monthly NDVI varied greatly, both temporally and spatially. In tropical East Asia, NDVI was high year-round. In the temperate and arctic zones, NDVI varied greatly with the season. The Tibetan Plateau, Gobi Desert, and Taklimakan Desert had low NDVI year-round. Average NDVI was highest on tropical islands (e.g. Borneo, Sumatra, and Sulawesi) and the mountain ranges of Indochina. It was lowest in the Taklimakan Desert, Gobi Desert, and northern Siberia (Fig. 3).

Average NDVI correlated significantly, positively with BSR $\left(R^{2}=0.59, P<0.001\right)$. NDVI explained $65 \%$ of the variation in mainland BSR $(P<0.001)$ (Fig. $4 \mathrm{a})$ but only $28 \%$ of the variation in island BSR $(P<0.001)$ (Fig. $4 \mathrm{~b})$.

\section{Topographic heterogeneity}

Elevation range was high in the Himalayas and Tienshan and Kunlunshan ranges, and on some islands in the Western Pacific Ocean, including Java, Sumatra, Sulawesi and Taiwan. Elevation range positively correlated with BSR (slope $=0.0244, t=16.9, P<0.001$ ) but only explained a small proportion of the variation in BSR $\left(R^{2}=0.08\right)$. Elevation range correlated positively with the BSR of mainland quadrats (slope $=0.0246, t=17.0, P<0.001, R^{2}=0.09$ ). It did not, however, correlate significantly with the BSR of island quadrats (slope $=0.0063, t=1.0, P=0.32$ ).

\section{Population density}

Human populations are unevenly distributed in East Asia. Some areas are densely populated (density $>1000$ person $\mathrm{km}^{-2}$ ), while vast areas, including the Tibetan Plateau and Taklimakan Desert, are virtually unpopulated (density $<1$ person $\mathrm{km}^{-2}$ ). Population density positively correlated with BSR (slope $=0.162, t=11.1, P<0.001$ ) but only explained $3 \%$ of the variation in BSR. Population density correlated positively with the BSR of mainland quadrats (slope $=0.231$, $\left.t=11.8, P<0.001, R^{2}=0.04\right)$. It did not, however, correlate significantly with the BSR of island quadrats (slope $=0.032$, $t=0.49, P=0.63)$. 


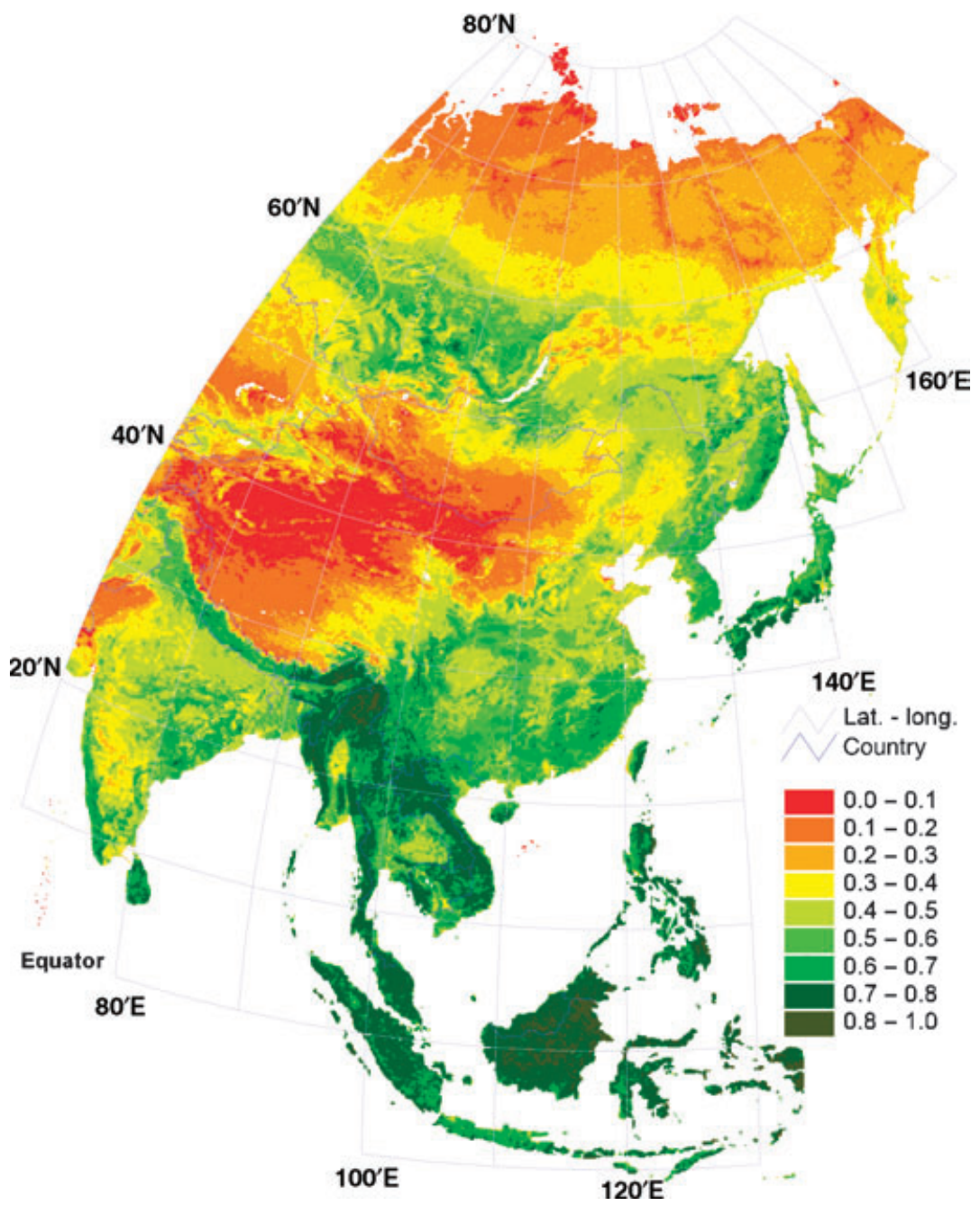

Figure 3 The average NDVI (normalized difference vegetation index) from 1988 to 2000 in East Asia. NDVI was highest in the tropical islands and mountain ranges of the Indochina Peninsula and lowest in the Taklimakan Desert, Gobi Desert, and northern Siberia. The higher the positive NDVI value, the greener the vegetation. Negative NDVI values indicate non-vegetated surface features such as water, barren land, ice, and snow.

\section{Multiple regressions}

Stepwise forward multiple regression (criterion for inclusion and exclusion, $P<0.05$ ) was applied to evaluate the statistical explanatory power of NDVI, elevation range, and population density on mainland BSR. In OLS models, NDVI explained $65.4 \%$ of the variance in mainland BSR $(P<0.001)$. Elevation range explained an additional 5.7\% $(P<0.001)$, and population density explained only an additional $0.1 \% \quad(P=0.007)$ (Table 2). Notably, population density positively correlated with mainland BSR in a simple linear regression but negatively correlated with the residuals of mainland BSR once the effects of NDVI and elevation range had been removed. In CAR models, eight trend surface terms of spatial coordinates $\left(x, y, x^{2}, x y, y^{2}, x^{3}\right.$, $\left.x^{2} y, x y^{2}\right)$ were included. After the effect of trend surface terms had been removed, NDVI explained an additional $25.7 \%$ of the variance in mainland $\operatorname{BSR}(P<0.001)$, elevation range explained $1.8 \%(P<0.001)$, and population density explained only an additional $0.2 \%(P=0.007)$ (Table 3$)$.

For island BSR, island area and distance to the mainland were added to the multiple regression analysis. All the variables were log-transformed to meet the assumption of normality for regression analysis and to overcome the inconsistent variance of the errors. NDVI explained $66.2 \%$ of variance in island BSR per quadrat $(P<0.001)$, island area explained an additional $14.9 \%(P<0.001)$, and distance to mainland explained an additional $0.8 \%(P<0.001)$ (Table 4$)$. Elevation range, population density, and land area of quadrat were excluded in the final model because of their insignificant contributions.

\section{DISCUSSION}

Most biogeographers now are convinced that species diversity is governed by multiple processes that function at a variety of spatial and temporal scales (Brown \& Lomolino, 1998; Gaston \& Blackburn, 2000; Whittaker et al., 2001). Most discussion focuses on which processes are primary and which are secondary. Brown \& Lomolino (1998) argued that the primary hypotheses should relate to some abiotic characteristics of the Earth, and those hypotheses (e.g. interspecific competition begets species diversity) that rely purely on biological characteristics and make no direct reference to the Earth's abiotic template should be secondary. In this study, we found that the results did not completely support the latitudinal 
(a)

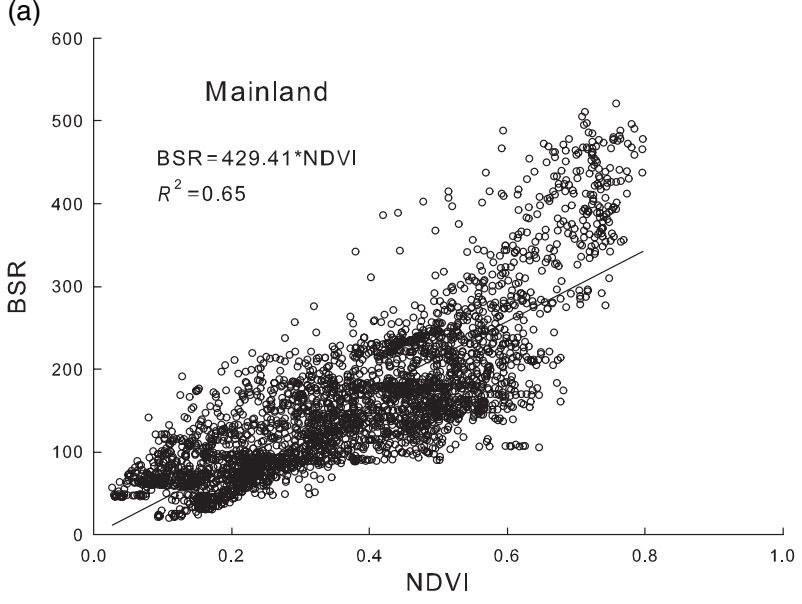

(b)



Figure 4 Bird species richness correlated significantly with average normalized difference vegetation index (1988-2000) on (a) mainland quadrats and (b) island quadrats.

Table 2 Stepwise forward multiple regressions (ordinary least squares model) of mainland bird species richness. NDVI explained mainland bird species richness better than elevation range or population density (d.f. $=3088$ )

\begin{tabular}{lllllr}
\hline Variable & Order & $\begin{array}{l}\text { Standard } \\
\text { coefficient }\end{array}$ & $\begin{array}{l}\text { Partial } \\
r^{2}\end{array}$ & $\begin{array}{l}\text { Model } \\
r^{2}\end{array}$ & Prob. $>t$ \\
\hline NDVI & 1 & 0.802 & 0.654 & 0.654 & $<0.001$ \\
Elevation range & 2 & 0.237 & 0.057 & 0.711 & $<0.001$ \\
Population density & 3 & -0.028 & 0.001 & 0.712 & 0.007 \\
\hline
\end{tabular}

gradient. In East Asia, highest BSR is located in the Tropic of Cancer, contrary to in other continents, where highest BSR is mostly located around the equator (Orme et al., 2005). Here we discuss three hypotheses that are often considered as primary causes of the latitudinal diversity gradient: the time hypothesis, energy limitation hypothesis, and area hypothesis. In addition, the spatial heterogeneity hypothesis and the effect of human population density are discussed.

\section{Time hypothesis}

The time hypothesis holds that higher latitudes have younger communities than lower latitudes because of the Pleistocene glaciations and severe climatic disruptions in the past. If the time hypothesis is correct, the most glaciated areas should have the lowest species richness. That is, higher latitudes and altitudes are expected to have lower species richness. In this study, within the band between $50^{\circ}$ and $80^{\circ} \mathrm{N}$, BSR declined monotonically with latitude, which is consistent with the prediction of the time hypothesis. However, within the band between $35^{\circ}$ and $80^{\circ} \mathrm{N}$, BSR was higher in the Tienshan Mountains and mountain ranges in southern Siberia and northern Mongolia. These mountain ranges were heavily glaciated in the Pleistocene and even served as centres of glaciation during earlier glacial stages (Ono et al., 2004). Based on the prediction of the time hypothesis, BSR in these mountain ranges should be lower than in the adjacent regions of similar latitudes. However, BSR was higher in these highly glaciated regions. Similar patterns also have been observed in Europe and temperate North America. BSR is relatively higher at mid-latitudes in Europe (Araújo et al., 2005) and in the Rocky Mountains and Sierra Nevada in North America (Hurlbert \& White, 2005). All these regions were heavily glaciated in the Pleistocene.

Although historical factors can affect contemporary species diversity, there is no significant effect of the Pleistocene glaciation on BSR in East Asia. Many bird species migrate and disperse over long distances. Their strong dispersal ability should, on average, enable birds to colonize newly available habitats within a relatively short period of time. Thus, the effects of Pleistocene disturbances might have been too short-lived to affect contemporary BSR. Therefore, patterns of BSR in East Asia probably are regulated primarily by ecological processes, such as energy availability and spatial heterogeneity, that function on a relatively short temporal scale.

\section{Area hypothesis}

The area hypothesis extends the species-area relationship and posits that the larger land area at lower latitudes increases species richness by decreasing extinction rates and increasing allopatric speciation. In East Asia, the temperate zone has much larger land areas than the tropics. If the area hypothesis is correct, BSR should correlate closely to land area along the latitudinal gradient and BSR should be very high in vast, temperate East Asia. Our results did not support this prediction. BSR was highest in tropical and subtropical East Asia, which was smaller in area but had higher primary productivity. We rejected the area hypothesis because it did not explain the overall latitudinal BSR gradient in East Asia.

On a global scale, land area and species richness are indeed greater in the Tropics than in other zones. However, terrestrial tropical ecosystems occur in three isolated regions: America, Africa, and Asia-Australia. Each is far away from the others, 


\begin{tabular}{llllll}
\hline Variable & Order & $\begin{array}{l}\text { Standard } \\
\text { coefficient }\end{array}$ & $\begin{array}{l}\text { Partial } \\
r^{2}\end{array}$ & $\begin{array}{l}\text { Model } \\
r^{2}\end{array}$ & Prob. $>t$ \\
\hline $\begin{array}{l}\text { Spatial variables } \\
\quad\left(x, y, x^{2}, x y, y^{2}, x^{3}, x^{2} y, x y^{2}\right)\end{array}$ & 1 & - & 0.721 & 0.721 & \\
NDVI & 2 & 0.705 & 0.257 & 0.978 & $<0.001$ \\
Elevation range & 3 & 0.146 & 0.018 & 0.996 & $<0.001$ \\
Population density & 4 & -0.068 & 0.002 & 0.998 & $<0.001$ \\
\hline
\end{tabular}

Table 3 Stepwise forward multiple regressions (conditional autoregressive model) of mainland bird species richness. NDVI explained mainland bird species richness better than elevation range or population density after the effect of eight spatial coordinate variables had been removed (d.f. $=3088)$
Table 4 Stepwise forward multiple regressions (ordinary least squares model) of island bird species richness. NDVI explained island bird species richness better than island area or distance to the mainland (d.f. $=343$ )

\begin{tabular}{|c|c|c|c|c|c|}
\hline Variable & Order & $\begin{array}{l}\text { Standard } \\
\text { coefficient }\end{array}$ & $\begin{array}{l}\text { Partial } \\
r^{2}\end{array}$ & $\begin{array}{l}\text { Model } \\
r^{2}\end{array}$ & Prob. $>t$ \\
\hline NDVI & 1 & 0.718 & 0.662 & 0.662 & $<0.001$ \\
\hline Island area & 2 & 0.401 & 0.149 & 0.811 & $<0.001$ \\
\hline Distance to mainland & 3 & -0.089 & 0.008 & 0.819 & $<0.001$ \\
\hline
\end{tabular}

${ }^{\star}$ All the variables were $\log$ transformed.

and the three regions share few common bird species. Therefore, the vast area and rich avifauna of the other two tropical regions have little or no effect on reducing extinction rates or increasing the colonization rates of bird species in tropical Asia.

In isolated areas, area correlated strongly with BSR. Larger islands tended to have more bird species, which was consistent with the expectations of island biogeography theory (MacArthur \& Wilson, 1967). This relationship still held after the effect of primary productivity (NDVI) was incorporated. Although area alone cannot explain latitudinal variation in BSR in East Asia, it does explain much of the variation in species richness in isolated areas.

\section{Energy limitation hypothesis}

The energy limitation hypothesis proposes that, in a given area, higher primary productivity can support more species because, in general, species can maintain larger populations and avoid extinction. In many local-scale studies, the relationship between species richness and primary productivity is humpshaped (Tilman, 1988; Rosenzweig, 1995), which does not support the energy limitation hypothesis. At the continental scale, however, primary productivity and the species richness of a variety of plant and animal groups often exhibit a positive monotonic relationship (e.g. Currie \& Paquin, 1987; Waide et al., 1999; Gaston, 2000; Hawkins et al., 2003, 2005; Whittaker \& Heegaard, 2003; Bini et al., 2004). In our study, BSR correlated positively and monotonically with primary productivity in East Asia, especially on mainland East Asia, where BSR correlated significantly with NDVI. The highest BSR was located on some mountains of Indochina, which had the highest primary productivity on mainland East Asia.
On islands, the correlation between primary productivity and BSR was not strong. All islands had fewer bird species than adjacent mainland areas, even though primary productivity and topographic heterogeneity were as high as or higher than on the islands. Some of the paired samples were: southern Japan and Korea, Taiwan and southern China, the Philippines and Vietnam, Sri Lanka and southern India, Borneo and the Malay Peninsula. The impoverishment of island biota can be attributed to the isolation of islands. The water around islands acts as a barrier that reduces immigration, making mainland species less likely to colonize islands, and species on islands more vulnerable to extinction (MacArthur \& Wilson, 1967). The isolation effect explains why the highest BSR was located on the mountains of Indochina, instead of on the isolated tropical islands where primary productivity was highest. Among the tropical islands, larger islands tended to have more bird species than smaller islands, although primary productivity was similar.

Overall, primary productivity explains a significant amount of the variation in BSR in East Asia. Our results indicate that primary productivity is the best factor of those considered herein in explaining BSR in East Asia. Other factors explained some of the fine-scale BSR patterns, but not the overall pattern.

\section{Spatial heterogeneity}

The spatial heterogeneity hypothesis posits that more diverse physical and biotic habitat structure permits finer subdivision of limiting resources and hence promotes greater specialization of species. For terrestrial birds, habitat heterogeneity can be split into landscape heterogeneity and the structural complexity of vegetation. MacArthur and his associates (MacArthur \& MacArthur, 1961; MacArthur et al., 1966) studied bird species diversity and habitat characteristics in different North American habitats and found that bird species diversity was highly correlated with foliage height diversity. Since then, the structural complexity of vegetation has been considered as a possible cause of the latitudinal diversity gradient (e.g. Pianka, 1966). However, the structural complexity of vegetation might not be a direct cause of species richness, but the product of others factors that also affect species richness. Historic perturbations and productivity could affect both species richness and the structural complexity of vegetation. In addition, the structural complexity of vegetation is a product of the plants and might be a consequence of species richness rather than a cause. Hence the structural complexity of 
vegetation is not likely to be a primary process for species richness along the latitudinal gradient.

Landscape heterogeneity has been widely used as an estimate of spatial heterogeneity at regional and continental scales (e.g. Kerr \& Packer, 1997). At these scales, more habitats (vegetation type, land cover, or ecosystem) will enable more species that specialize in certain habitats to occur together, increasing species richness. Landscape heterogeneity explains a large amount of the variation in species richness at broad spatial scales (Kerr \& Packer, 1997). It correlates with island area and is often used to explain the species-area relationship (MacArthur \& Wilson, 1967). Landscape heterogeneity does not, however, vary consistently with latitude. Higher latitudes do not necessarily have lower landscape heterogeneity than lower latitudes. Therefore, landscape heterogeneity is often used as a secondary or independent process affecting species richness on the latitudinal gradient.

\section{Population density}

Higher human population densities usually cause more anthropogenic perturbations and could alter species diversity in natural ecosystems. Because East Asia contains half of the world population and has been extensively colonized for thousands of years, we analysed the relationship between human population density and BSR. We found that human population density was positively, though weakly, correlated with BSR in East Asia. This does not necessarily imply that increases in human population density beget increases in BSR. Instead, human population density, BSR, and other factors, such as primary productivity, could be correlated (Araújo, 2003; Gaston \& Evans, 2004). For example, humans might avoid dwelling in areas with low productivity where conditions are not suitable for agriculture. After the effect of primary productivity was removed, human population density was significantly negatively correlated with BSR.

Human disturbance and urbanization usually negatively affect BSR at local and regional scales (Jokimäki et al., 2002; McKinney, 2002; Lee et al., 2004). However, the effect of human population density on BSR might not be significant at continental scales. Although high population density can significantly modify natural ecosystems, rendering many species locally extinct or endangered, a few, small remnant habitats in a region may support small numbers of a species, which would then be recorded as present in the entire quadrat. Therefore, owing to the low resolution for both bird distributions and human population density, the precise relationship between human density and BSR cannot be adequately characterized at continental scales.

\section{ACKNOWLEDGEMENTS}

We thank Alan Warneke, Art Shapiro, Robert J. Whittaker, Susan Ustin, and two anonymous referees for their helpful suggestions. This research was supported by the Pacific Rim Research Program at the University of California, and the
National Science Council, Taiwan, Republic of China (NSC912621-B-002-017).

\section{REFERENCES}

An, Z.J., Kutzbach, E., Prell, W.L., Warren, L. \& Porter, S.C. (2001) Evolution of Asian monsoons and phased uplift of the Himalaya-Tibetan plateau since Late Miocene times. Nature, 411, 62-66.

Araújo, M.B. (2003) The coincidence of people and biodiversity in Europe. Global Ecology and Biogeography, 12, 5-12.

Araújo, M.B., Thuiller, W., Williams, P.H. \& Reginster, I. (2005) Downscaling European species atlas distributions to a finer resolution: implications for conservation planning. Global Ecology and Biogeography, 14, 17-30.

Bini, L.M., Diniz-Filho, J.A.F. \& Hawkins, B.A. (2004) Macroecological explanations for differences in species richness gradients: a canonical analysis of South American birds. Journal of Biogeography, 31, 1819-1827.

Brown, J.H. \& Lomolino, M.V. (1998) Biogeography, 2nd edn. Sinauer, Sunderland, MA.

Connell, J.H. \& Orias, E. (1964) The ecological regulation of species diversity. The American Naturalist, 98, 399-414.

Currie, D.J. \& Paquin, V. (1987) Large-scale biogeographical patterns of species richness of trees. Nature, 329, 326-327.

Diniz-Filho, J.A.F., Bini, L.M. \& Hawkins, B.A. (2003) Spatial autocorrelation and red herrings in geographical ecology. Global Ecology and Biogeography, 12, 53-64.

Dobzhansky, T. (1950) Evolution in the tropics. The American Naturalist, 14, 64-81.

ESRI (Environmental System Research Institute) (1996) ArcAtlas: Our Earth. CD-ROMs. ESRI, Redlands.

Fischer, A.G. (1960) Latitudinal variations in organic diversity. Evolution, 14, 64-81.

Gaston, K.J. (2000) Global patterns in biodiversity. Nature, 405, 220-227.

Gaston, K.J. \& Blackburn, T.M. (2000) Pattern and process in macroecology. Blackwell Science Ltd, Oxford.

Gaston, K.J. \& Evans, K.L. (2004) Birds and people in Europe. Proceedings of the Royal Society of London Series B, Biological Sciences, 271, 1649-1655.

Hawkins, B.A. (2004) Summer vegetation, deglaciation and the anomalous bird diversity gradient in eastern North America. Global Ecology and Biogeography, 13, 321-325.

Hawkins, B.A., Field, R., Cornell, H.V., Currie, D.J., Guegan, J.F., Kaufman, D.M., Kerr, J.T., Mittelbach, G.G., Oberdorff, T., O'Brien, E.M., Porter, E.E. \& Turner, J.R.G. (2003) Energy, water, and broad-scale geographic patterns of species richness. Ecology, 84, 3105-3117.

Hawkins, B.A., Diniz, J.A.F. \& Soeller, S.A. (2005) Water links the historical and contemporary components of the Australian bird diversity gradient. Journal of Biogeography, 32, 1035-1042.

Henningsson, S.S. \& Alerstam, T. (2005) Patterns and determinants of shorebird species richness in the circumpolar Arctic. Journal of Biogeography 32, 383-396. 
Hillebrand, H. (2004) On the generality of the latitudinal diversity gradient. The American Naturalist, 163, 192-211.

Holben, B.N. (1986) Characteristics of maximum-value composite images from temporal AVHRR data. International Journal of Remote Sensing, 11, 1417-1434.

Hurlbert, A.H. \& White, E.P. (2005) Disparity between range map- and survey-based analyses of species richness: patterns, processes and implications. Ecology Letters, 8, 319-327.

Jokimäki, J., Clergeau, P. \& Kaisanlahti-Jokimäki, M.L. (2002) Winter bird communities in urban habitats: a comparative study between central and northern Europe. Journal of Biogeography, 29, 69-79.

Kaluzny, S.P., Vega, S.C., Cardoso, T.P. \& Shelly, A.A. (1998) $S+$ SpatialStats: user's manual for Windows and UNIX. Springer, New York.

Kerr, J.T. \& Packer, L. (1997) Habitat heterogeneity as a determinant of mammal species richness in high-energy regions. Nature, 385, 252-254.

Klopfer, P.H. (1959) Environmental determinants of faunal diversity. The American Naturalist, 93, 337-342.

Lee, P.F., Ding, T.S., Hsu, F.H. \& Geng, S. (2004) Breeding bird species richness in Taiwan: distribution on gradients of elevation, primary productivity and urbanization. Journal of Biogeography, 31, 307-314.

Lichstein, J.W., Simons, T.R., Shriner, S.A. \& Franzreb, K.E. (2002) Spatial autocorrelation and autoregressive models in ecology. Ecological Monographs, 72, 445-463.

Loveland, T.R., Reed, B.C., Brown, J.F., Ohlen, D.O., Zhu, Z., Yang, L. \& Merchant, J.W. (2000) Development of a global land cover characteristics database and IGBP DISCover from $1 \mathrm{~km}$ AVHRR data. International Journal of Remote Sensing, 21, 1303-1330.

MacArthur, R.H. \& Connell, J.H. (1966) The biology of populations. Wiley, New York.

MacArthur, R.H. \& MacArthur, J.W. (1961) On bird species diversity. Ecology, 42, 594-598.

MacArthur, R.H. \& Wilson, E.O. (1967) The theory of island biogeography. Princeton University Press, Princeton, NJ.

MacArthur, R.H., Recher, H. \& Cody, M. (1966) On the relation between habitat selection and species diversity. The American Naturalist, 100, 319-332.

Matsushita, B. \& Tamura, M. (2002) Integrating remotely sensed data with an ecosystem model to estimate net primary productivity in East Asia. Remote Sensing of Environment, 81, 58-66.

McKinney, M.L. (2002) Urbanization, biodiversity, and conservation. Bioscience, 52, 883-890.

Monroe, B.L. \& Sibley, C.G. (1993) A world checklist of birds. Yale University Press, New Haven, CT.

Ono, Y., Shulmeister, J., Lehmkuhl, F., Asahi, K. \& Aoki, T. (2004) Timings and causes of glacial advances across the PEP-II transect (East-Asia to Antarctica) during the last glaciation cycle. Quaternary International, 118, 55-68.

Orme, C.D.L., Davies, R.G., Burgess, M., Eigenbrod, F., Pickup, N., Olson, V.A., Webster, A.J., Ding, T.S., Rasmussen, P.C., Ridgely, R.S., Stattersfield, A.J., Bennett, P.M., Black- burn, T.M., Gaston, K.J. \& Owens, I.P.F. (2005) Global hotspots of species richness are not congruent with endemism or threat. Nature, 436, 1016-1019.

Paine, R.T. (1966) Food web complexity and species diversity. The American Naturalist, 100, 65-75.

Pianka, E.R. (1966) Latitudinal gradients in species diversity: a review of the concepts. The American Naturalist, 100, 33-46.

Rahbek, C. \& Graves, G.R. (2001) Multiscale assessment of patterns of avian species richness. Proceedings of the National Academy of Sciences of the United States of America, 98, 4534-4539.

Rohde, K. (1992) Latitudinal gradients in species diversity: the search for the primary cause. Oikos, 65, 514-527.

Rosenzweig, M.L. (1995) Species diversity in space and time. Cambridge University Press, Cambridge, UK.

Terborgh, J. (1973) On the notion of favourableness in plant ecology. The American Naturalist, 107, 481-501.

Tilman, D. (1988) Plant strategies and the dynamics and structure of plant communities. Princeton University Press, Princeton, NJ.

Tognelli, M.F. \& Kelt, D.A. (2004) Analysis of determinants of mammalian species richness in South America using spatial autoregressive models. Ecography, 27, 427-436.

Tucker, C.J. (1979) Red and photographic infrared linear combinations for monitoring vegetation. Remote Sensing of Environment, 8, 127-150.

Ustin, S.L., Wessman, C.A., Curtiss, B., Kasischke, E., Way, J. \& Vanderbilt, V.C. (1991) Opportunities for using the EOS imaging spectrometers and synthetic aperture radar in ecological models. Ecology, 72, 1934-1945.

Waide, R.B., Willig, M.R., Steiner, C.F., Mittelbach, G., Gough, L., Dobson, S.I., Juday, G.P. \& Parmenter, R. (1999) The relationship between productivity and species richness. Annual Review of Ecology and Systematics, 30, 257300.

Whittaker, R.J. \& Heegaard, E. (2003) What is the observed relationships between species richness and productivity? Comment. Ecology, 84, 3884-3990.

Whittaker, R.J., Willis, K.J. \& Field, R. (2001) Scale and species richness: towards a general hierarchical theory of species diversity. Journal of Biogeography, 28, 453-470.

Willig, M.R., Kaufman, D.M. \& Stevens, R.D. (2003) Latitudinal gradients of biodiversity: pattern, process, scale, and synthesis. Annual Review of Ecology, Evolution and Systematics, 34, 273-309.

Wright, D.H. (1983) Species-energy theory: an extension of species-area theory. Oikos, 41, 496-506.

\section{SUPPLEMENTARY MATERIAL}

The following supplementary material is available for this article online from http://www.Blackwell-Synergy.com

Appendix S1 Source literature used to derive breeding ranges of 2406 bird species in East Asia. 
BIOSKETCHES

Tzung-Su Ding is an assistant professor in the School of Forestry and Resource Conservation, National Taiwan University. His interests focus on species diversity and community ecology.

Hsiao-Wei Yuan is a professor in the School of Forestry and Resource Conservation, National Taiwan University. Her interests focus on bird ecology and wildlife management.

Shu Geng is a professor in agriculture and ecology at the University of California, Davis. His research focuses mainly on agricultural systems and the impact of climate change on food production.

Chao-Nien Koh is a PhD student in ecology and evolutionary biology at the National Taiwan University. Her main interest is the relationship between environmental factors and bird communities in Taiwan.

Pei-Fen Lee is a professor in ecology and evolutionary biology at the National Taiwan University. His work focuses mainly on landscape and community ecology, as well as on reserve design and management using GIS.

Editor: Robert Whittaker 